\section{Movimentos no projeto Cirandar: A Educação CTS e Freireana articuladas com a temática dos agrotóxicos em teses e dissertações}

\author{
Movements in the Cirandar project: STS and \\ Freirean Education articulated with the theme of \\ pesticides in theses and dissertations
}

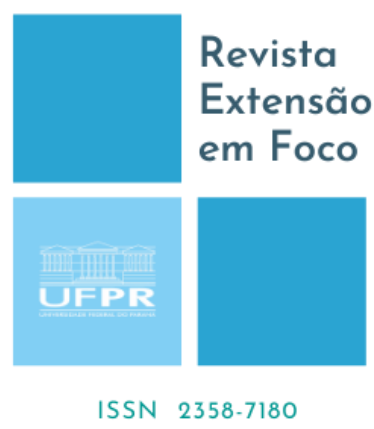

ISSN $2358-7180$

\author{
Sandra Mara Mezalira ${ }^{1}$ Vanessa Candito ${ }^{2}$ Alberto Bracagioli Neto ${ }^{3}$ José Vicente Lima \\ Robaina $^{4}$
}

RESUMO

\begin{abstract}
A educação em ciências desenvolvida nos currículos das instituições de ensino é uma das possibilidades para transformar a vida das pessoas para melhor, por meio da consciência crítica e da tomada de decisões frente aos diversos fenômenos do cotidiano. Dessa forma, a pesquisa buscou fazer um levantamento bibliográfico das pesquisas sobre o viés da Educação Freireana e Ciência, Tecnologia e Sociedade (CTS), articulados a temática dos Agrotóxicos no ensino de Ciências, por meio de teses e dissertações de plataformas de publicações cientificas da Biblioteca Digital Brasileira de Teses e Dissertações e o Catálogo de Teses e Dissertações da Capes compreendidas no período de 2008 a 2020. Encontrou-se 11 produções acadêmicas, organizadas em nove dissertações e duas teses. Verificou-se, assim, articulações com os principais descritores encontrados, que foram representados em duas nuvens de palavras. As pesquisas analisadas retratam uma articulação envolvendo o enfoque CTS/Ciência, Tecnologia, Sociedade e Ambiente (CTSA)/Pensamento Latino Americano em Ciência, Tecnologia e Sociedade, conceitos relacionados a perspectiva freireana e os agrotóxicos. Foi possível perceber, também, que dos onze trabalhos selecionados, sete deles trataram CTS na perspectiva de CTSA, dando maior visibilidade ao aspecto do Ambiente, remetendo a problemática ambiental dos agrotóxicos. A perspectiva freireana se destaca por meio do diálogo e da problematização que são categorias centrais nas discussões de Paulo Freire.
\end{abstract}

Palavras-chave: Currículo. Ciência e Tecnologia. Método Paulo Freire.

\title{
ABSTRACT
}

Science education developed in the curricula of educational institutions is one of the possibilities for transforming people's lives for the better, through critical awareness and decision-making in the face of various everyday phenomena. Thus, the research sought to make a bibliographic survey of research on the bias of Freirean Education and Science, Technology and Society (STS), articulating the theme of Pesticides in Science teaching, through theses and dissertations from scientific publications platforms of the Brazilian Digital Library of Theses and Dissertations and Capes' Theses and Dissertations Catalog, included from 2008 to 2020 . There were 11 academic productions, organized into nine dissertations and two theses. Thus, it was found articulations with the main descriptors found, which were represented in

\footnotetext{
${ }^{1}$ Doutoranda no Programa de Pós-Graduação em Educação em Ciências: Química da Vida e Saúde, (UFRGS); Porto Alegre, Rio Grande do Sul, Brasil; sandmezal@gmail.com; ORCID: 0000-0002-3326-0322.

2 Mestranda no Programa de Pós-Graduação em Educação em Ciências: Química da Vida e Saúde, (UFRGS); Porto Alegre, Rio Grande do Sul, Brasil; vanecandito@gmail.com; ORCID: 0000-0003-4663-9590.

${ }^{3}$ Professor do Departamento de Horticultura e Silvicultura da Faculdade de Agronomia e do Programa de Pósgraduação em Desenvolvimento Rural (UFRGS); Porto Alegre, Rio Grande do Sul, Brasil; abracagioli@gmail.com; ORCID: 0000-0002-3947-2289.

${ }^{4}$ Professor do Departamento de Ensino e Currículo da Faculdade de Educação (UFRGS), professor e orientador da Licenciatura em Educação do Campo-Ciências da Natureza e do Programa de Pós-graduação em Educação em Ciências: Química da Vida e Saúde; Porto Alegre, Rio Grande do Sul, Brasil; joserobaina1326@ gmail.com; ORCID: 0000-0002-4604-3597.
} 
two word clouds. The analyzed researches portray an articulation involving the STS/Science, Technology, Society and Environment (STSE)/Latin American Thought in Science, Technology and Society, concepts related to the Freirean perspective and pesticides. It was also possible to perceive that of the eleven selected works, seven of them dealt with STS from the perspective of STSE, giving greater visibility to the aspect of the Environment, referring to the environmental problem of pesticides. The Freirean perspective stands out through dialogue and problematization, which are central categories in Paulo Freire's discussions.

Keywords: Curriculum. Science and Technology. Paulo Freire Method.

\section{CONSIDERAÇÕES INICIAIS}

A Ciência tem avançado em pesquisas no intuito de melhorar a vida das pessoas, porém, desdobramentos dela têm afetado de modo negativo alguns campos, como o da saúde e do meio ambiente. A produção dos transgênicos e dos agrotóxicos, a construção de usinas hidrelétricas, as bombas atômicas, a indústria alimentícia, entre outros são alguns exemplos do mau uso da Ciência e Tecnologia (CT).

De acordo com Auler (2018), a degradação socioambiental depende muito da ação humana. Depende, também, dos diversos setores sociais envolvidos e engajados na causa ambiental, que historicamente têm sido silenciados pela ganância e sagacidade dos opressores. A sociedade tem muito a aprender, a avançar, especialmente no que tange à influência exercida pelo capitalismo sobre o sistema produtivo, incluindo a Ciência e Tecnologia. "Uns poucos, os donos do capital, dos meios de produção, concebem a organização de tal produção enquanto que, os que vendem seu trabalho, os trabalhadores, meramente executam a ação concebida por aqueles" (AULER, 2018, p. 19).

O currículo escolar não é diferente desse processo: ele encontra, como na organização fabril, a sua lógica, a sua inspiração. A revolução industrial transformou a vida de todas as pessoas, inclusive na forma de conduzir a educação. A educação bancária denunciada por Paulo Freire, nos mostra a concepção advinda das fábricas, fundamentando o currículo. Alguns poucos (os técnicos) concebem o currículo e muitos (os professores) executam, visando quase que exclusivamente o "cumprimento" da matriz curricular e o "vencimento" dos conteúdos de modo disciplinar. Assim, o processo escolar faz-se semelhante ao das fábricas. O capital pauta ou controla Políticas CientíficoTecnológicas, produtos e currículos (AULER, 2018).

Para tanto, algumas propostas curriculares em diferentes níveis de ensino têm investido em abordagens que se comprometem com a Alfabetização Científica e Tecnológica dos indivíduos para compreender a ocorrência dos fenômenos naturais, 
políticos, econômicos e sociais na sua totalidade. Uma das abordagens possíveis é o enfoque da Ciência, Tecnologia e Sociedade (CTS).

Nesse sentido, o objetivo desse estudo iniciado no projeto Cirandar, edição 2020, foi realizar uma Revisão Bibliográfica por meio do mapeamento de pesquisas encontradas nas bases de dados da Biblioteca Digital Brasileira de Teses e Dissertações (BDTD) e do Catálogo de Teses e Dissertações da Capes (CTD) e que comtemplassem os descritores “CTS AND Paulo Freire AND Agrotóxicos no ensino de ciências" no período de 2008 a 2020 e a partir disso verificar e refletir sobre as articulações realizadas entre CTS, Paulo Freire e Agrotóxicos nas produções selecionadas.

\section{A PERSPECTIVA CTS E FREIREANA NA EDUCAÇÃO EM CIÊNCIAS}

A Educação CTS emergiu após longas discussões a posteriori do movimento CTS ocorrido nas décadas de 1960 e 1970 na Europa, Estados Unidos e nos países latino americanos, inclusive no Brasil. Este movimento introduziu a crítica ao modelo desenvolvimentista permeado de forte impacto ambiental, difundindo a reflexão sobre o papel da ciência e da tecnologia na sociedade, com uma perspectiva de formação para a cidadania. Um exemplo dessa movimentação efervescente, foi a publicação do livro Primavera Silenciosa de Rachel Carson (2010), livro que denuncia a presença de agrotóxicos que prejudicam o ambiente pelos seus efeitos nocivos.

Conforme Auler (2011), parte-se do pressuposto de que a superioridade e a neutralidade do modelo de decisões tecnocráticas, supõe a possibilidade de anular ou eliminar a participação das pessoas no processo científico e tecnológico. De que os especialistas podem solucionar os problemas sociais de forma eficiente e neutra, portanto, eliminando os conflitos ideológicos e/ou de interesse, nesse sentido o diálogo é importante. Freire (2019, p.111) diz: "Como posso dialogar, se me sinto participante de um gueto de homens puros, donos da verdade e do saber, para quem todos os que estão fora são 'essa gente', ou são 'nativos inferiores'?” E, ainda, não é no silêncio que as pessoas se fazem, mas na palavra, no trabalho, na ação-reflexão. O diálogo é o encontro entre a humanidade, mediatizados pelo mundo para então pronunciá-lo, na relação eu e tu, no amor ao próximo, na humildade (FREIRE, 2019).

Contudo, o mito, historicamente construído, de que a Ciência e Tecnologia resolverão todos os problemas da humanidade, conduzindo ao Bem Estar Social, atribuindo, assim, um caráter salvacionista a CT, também, precisa ser discutido e 
superado. Esta ideia ignora as relações sociais em que a CT é criada e utilizada. Um modelo disso são os muros cada vez mais altos, cercas eletrificadas, alarmes, circuitos internos de TV, supondo-se que a solução contra a violência seja técnica, esperando-se que esses aparatos nos protejam da violência e assim, acaba-se por naturalizar a violência ao invés de problematizar o modelo socioeconômico que promove a insegurança (AULER, 2011). Desse modo, se faz necessário ponderar não apenas as implicações e impactos da CT, mas também o processo que os antecede, como as questões política e econômica envolvidas, para podermos, como cidadãos críticos e facilitadores do conhecimento, participar da construção de políticas públicas de CT.

Paulo Freire (2016) nos faz refletir sobre a importância dos valores, dos conhecimentos do "saber da experiência feito" que muitas vezes são silenciados nos currículos, diz: "Ninguém deixa seu mundo, adentrando por suas raízes, com o corpo vazio e seco. Carregamos conosco a memória de muitas tramas, o corpo molhado de nossa história, de nossa cultura; a memória, as vezes difusa, às vezes nítida, clara, de ruas da infância, da adolescência” (p. 45). Ressalta ainda, que a esperança nasce da pedagogia que tem o oprimido como sujeito, implicando em uma denúncia das injustiças sociais e das opressões que vão permanecendo ao longo da história. Assim, “[ ...] ao mesmo tempo anuncia a capacidade humana de desfatalizar esta situação perversa e construir um futuro eticamente mais justo, politicamente mais democrático, esteticamente mais radiante e espiritualmente mais humanizador" (FREIRE, 2016, p.11).

Nessa perspectiva, há alguns anos se discute como minimizar as questões do desenvolvimento científico e tecnológico de modo que os cidadãos consigam compreender, de forma consciente e crítica, os fenômenos do cotidiano, para que possam tomar suas decisões e resolver seus problemas com responsabilidade. À vista disso, uma das maneiras de situar e utilizar a CT de forma crítica e consciente, tem se dado por meio do desenvolvimento de novas estratégias curriculares nas instituições de ensino.

Quando nos reportamos ao currículo, a educação da CTS e o Pensamento Latino Americano em Ciência, Tecnologia e Sociedade (PLACTS) surgem como possibilidades de transformação da prática escolar e, por consequência, da vivência social. Isto pode se dar por meio da problematização, reflexão e tomada de consciência com responsabilidade dos fenômenos cotidianos locais. Conforme Auler (2018), a investigação temática em Paulo Freire, é uma possibilidade de diálogo com os atores sociais, que dá visibilidade àqueles atores que foram apagados da história e pode possibilitar a entrada em cena de 
novas demandas, novos valores, potencializando novos currículos, novas agendas de pesquisa e novos processos produtivos.

Nesse sentido, Paulo Freire (2019), destaca a questão da educação bancária quando "a narração, de que o educador é o sujeito, conduz os educandos à memorização mecânica do conteúdo narrado" (p. 80). E, ao contrário, o autor menciona a educação problematizadora como potencializadora da educação para a liberdade, assim, "a educação problematizadora, respondendo à essência do ser da consciência, que é sua intencionalidade, nega os comunicados e existência a comunicação" (FREIRE, 2019, p. 94), implicando em um desvelamento da realidade. Na educação problematizadora, "ninguém educa ninguém, como tampouco ninguém se educa a si mesmo: os homens se educam em comunhão, mediatizados pelo mundo" (FREIRE, 2019, p. 96).

O denominado PLACTS surge num momento histórico em que está em pauta a denominada transferência tecnológica. Esse pensamento empreende uma práxis que questiona o modelo de industrialização. Alguns de seus representantes, como Varsavsky, Herrera e Sábato, na sua maioria, eram pesquisadores no campo das chamadas Ciências Naturais, vinculados a universidades argentinas. Eles, já nas décadas de 1960 e 1970, destacavam que, no processo de transferência tecnológica, não estavam sendo transferidas ferramentas neutras, mas modelos de sociedade. Também afirmavam que a dinâmica do desenvolvimento científico-tecnológico era alheia, isto é, ignorava as demandas do conjunto da sociedade latino-americana.

No contexto latino americano, o PLACTS, considera a história do país, a sua localidade, elementos que são comuns neste espaço, tendo a participação em processos decisórios como elemento essencial. Conforme Auler (2011, p. 74) o PLACTS leva em consideração os elementos:

Participação na definição de rumos do desenvolvimento científicotecnológico, na definição da agenda de pesquisa, e não apenas, como é hegemônico no campo CTS, na avaliação dos impactos pós-produção. Parte-se do pressuposto de que a atual agenda de pesquisa não atende as demandas do conjunto da sociedade latino-americana, sendo também, ambientalmente insustentável.

Décio Auler (2011) nos chama a atenção para um currículo que potencialize mecanismos de participação. Participação na sociedade, também, na definição de parâmetros em relação a Política Científico e Tecnológica (PCT), e não apenas, como é hegemônico no campo CTS, na avaliação dos impactos da pós-produção. Assim, é necessário pensar nesse outro viés de reflexão CTS que é pensar a CT antes mesmo da 
sua produção. É indispensável que as pessoas possam participar das decisões em relação à Ciência e Tecnologia, participando das leis e decretos elaborados para o desenvolvimento da Ciência.

Para Auler e Delizoicov (2015), tanto Paulo Freire como o PLACTS, constituem pressupostos comuns, visto que em ambos postula-se a superação da separação entre concepção e execução. Para os mesmos autores:

Na concepção educacional bancária, foco principal da crítica de Freire, alguns concebem o currículo, outros o executam. No campo da ciênciatecnologia (CT), executa-se, no contexto latino-americano, segundo os representantes do PLACTS, uma agenda de pesquisa concebida no Hemisfério Norte. (AULER; DELIZOICOV, 2015, p. 278).

Varsavsky (1976), já naquela época alertava para que a CT de países desenvolvidos não fosse copiada por países da América Latina. A realidade, o contexto é outro, não somos países de primeiro mundo. Nesse sentido, para Auler (2011), o currículo precisa ser radicalmente modificado, de forma que este possa potencializar a compreensão, a participação em debates, a tomada fundamentada de decisões, em temas sociais, marcados pela CT, por sua natureza complexos, que “[...] não abarcáveis por um único campo disciplinar e, numa perspectiva de democratização, não restrito ao campo técnico-científico" (AULER, 2011, p. 91). Conforme o mesmo autor, um caminho consistente é possível a partir da estrutura de temas, de problemas reais, de controvérsias, como ponto de partida e os conteúdos sendo trabalhados posteriormente (AULER, 2011).

Paulo Freire (2019), nos traz a possibilidade de trabalhar temas, a partir da investigação temática realizada no contexto, por todos que fazem parte daquela comunidade: estudantes, professores e pais, por isso, “[...] será a partir da situação presente, existencial, concreta, refletindo o conjunto de aspirações do povo, que poderemos organizar o conteúdo programático da educação ou da ação política” (p. 119). E ainda, “[...] o momento deste buscar é o que inaugura o diálogo da educação como prática da liberdade. É o momento em que se realiza a investigação do que chamamos de universo temático do povo ou o conjunto de seus temas geradores” (p. 121), pois, “[...] investigar o tema gerador é investigar, repitamos, o pensar dos homens referido à realidade, é investigar seu atuar sobre a realidade, que é sua práxis” (p.136).

É necessário repensar a educação CTS, a partir do âmbito do PLACTS, dando originalidade, incorporação crítica e participando na elaboração de parâmetros para a definição das Políticas Científicas e Tecnológicas. Conforme Auler e Delizoicov (2015), 
a articulação entre Freire-PLACTS, vislumbra a necessária participação da sociedade, em processos de tomada de decisões, sobre temas sociocientíficos, que em pesquisas e no currículo vem se reduzindo a uma avaliação dos impactos da CT na sociedade, a uma avaliação na pós-concepção e produção de CT, de modo a potencializar fatores estimados positivos e atenuar os avaliados como negativos. As duas perspectivas apontam para "[...] uma leitura crítica do mundo", para o "desvelamento da realidade", uma compreensão crítica sobre as interações entre ciência-tecnologia-sociedade" (AULER; DELIZOICOV, 2015, p. 281).

\section{CONTEXTO DO ESTUDO E ASPECTOS METODOLÓGICOS}

Como dito anteriormente, este artigo emerge dos diálogos do projeto de extensão "Cirandar: Rodas de investigação desde a escola" da Universidade Federal do Rio Grande (FURG), oriundo dos Encontros Riograndinos sobre Investigação na Escola FURG. Dirigido pela coordenação da FURG junto aos organizadores dos Polos regionais, na região Sul do Brasil, por meio da troca de três Cartas via e-mail entre as Cirandeiras e Cirandeiros e que resultam nesse escrito.

Na primeira Carta foi solicitado uma apresentação inicial do participante no projeto, na segunda Carta trouxe a apresentação de uma temática de pesquisa, aquilo que estava nos inquietando e que futuramente deveria ser aprofundado na terceira Carta. Essas escritas resultam em uma produção final, a qual é avaliada por uma leitura entre pares, com todos os participantes do projeto.

Dentro disso, não podemos deixar de demarcar o momento em que vivemos. Há quase dois anos, o mundo passa por uma das maiores pandemias: o novo coronavírus. Esses novos tempos, evidenciaram, ainda mais as mazelas enfrentadas cotidianamente por milhares de brasileiras e brasileiros. Desigualdade social, falta de acesso as tecnologias móveis, fome e desemprego, além dos problemas ambientais que aumentaram junto a pandemia, entre outros tantos. Somado a isso, uma onda negacionista invade a sociedade e é reafirmada, principalmente, pelo governo Federal. Assim, no ano de 2020 todo o projeto do Cirandar foi desenvolvido de forma virtual com encontros síncronos e assíncronos, e-mails, respeitando o distanciamento social, ocasionado pela pandemia.

Tratou-se de uma pesquisa de natureza qualitativa, com caráter exploratório e descritivo, e busca fazer um levantamento bibliográfico das pesquisas sobre o viés da Educação CTS e Freireana articulados a temática dos Agrotóxicos no ensino de Ciências. Trata-se de um método de pesquisa que busca mapear os estudos em que desvenda e 
examina o conhecimento já elaborado e aponta os enfoques, os temas mais pesquisados e as lacunas existentes (ROMANSKI; ENS, 2006).

As plataformas de publicações científicas selecionadas para tal pesquisa foram a BDTD e o CTD compreendidas no período de 2008 a 2020. A escolha destas bases de dados teve como critério de seleção a representatividade e abrangência nacional, constituindo os principais espaços para divulgação e discussão de teses e dissertações. Os trabalhos publicados nas bases de dados, encontram-se disponíveis online e podem ser acessados na sua íntegra nas plataformas mencionadas.

Para a seleção dos dados, procurou-se as dissertações e teses por meio dos seguintes verbetes: "Agrotóxicos", "CTS", "Paulo Freire" e "Ensino de Ciências". Os verbetes deveriam estar presentes no título das produções, nas palavras chave, nos resumos ou nos trabalhos completos, indicados pelos autores das pesquisas e ter relação com o ensino de ciências.

A análise dos dados deu-se, inicialmente, pela procura de todos os trabalhos que retornassem da busca na base de dados pesquisada. As publicações escolhidas foram identificadas por número, independentemente, de serem dissertações ou teses, por exemplo “01, 02 até 11”, e por códigos: BDTD e CTD. No decorrer das buscas e dos cruzamentos dos descritores fomos percebendo que resultavam, na maioria deles, nos mesmos trabalhos, independente dos descritores cruzados, conforme discutido nos resultados.

$\mathrm{Na}$ compilação e análise dos dados foram construídos quadros e nuvens de palavras (pelo site wordart.comt). A formação das nuvens de palavras se deu pela contagem de palavras somente uma vez que apareciam nas dissertações e teses. Foram selecionadas aquelas palavras que faziam relação com a perspectiva CTS e Freireana.

\section{RESULTADOS E DISCUSSÕES}

Foram obtidos um total de 11 produções acadêmicas a partir das duas bases pesquisadas, podendo organizá-las em nove dissertações e duas teses. Os trabalhos apresentavam período de abrangência entre 2008 a 2020. Estes foram selecionados para análise e são apresentados no quadro 1: 
Quadro 1 - Apresentação das bases de dados, identificação, ano, autor e título da pesquisa.

\begin{tabular}{|c|c|c|c|}
\hline *Ident. & Ano & Autor & Título \\
\hline CTD - 01 & 2009 & $\begin{array}{l}\text { ALMEIDA, } \\
\text { M.T. }\end{array}$ & $\begin{array}{l}\text { O Agrotóxico como Tema Problematizador no Ensino de } \\
\text { Química na Formação Técnico Agrícola }\end{array}$ \\
\hline CTD - 02 & 2012 & $\begin{array}{l}\text { GOTARDI, O. } \\
\text { L. N. }\end{array}$ & $\begin{array}{l}\text { Agrotóxicos e meio ambiente - abordagem CTS numa } \\
\text { perspectiva freireana para o ensino de química em } \\
\text { Culturama-MS }\end{array}$ \\
\hline $\begin{array}{l}\text { BDTD - } \\
03\end{array}$ & 2014 & $\begin{array}{l}\text { BUFFOLO, A. } \\
\text { C. C. }\end{array}$ & $\begin{array}{l}\text { Agrotóxicos: uma proposta socioambiental reflexiva para } \\
\text { desenvolver conhecimentos químicos numa perspectiva } \\
\text { CTS }\end{array}$ \\
\hline $\begin{array}{l}\text { BDTD } \\
04\end{array}$ & 2014 & CARMO, T. & $\begin{array}{l}\text { Aproximações entre a educação ambiental e o movimento } \\
\text { Ciência, Tecnologia e Sociedade: um olhar sobre } \\
\text { dissertações e teses no ensino de química }\end{array}$ \\
\hline $\begin{array}{l}\text { BDTD } \\
05\end{array}$ & 2016 & $\begin{array}{l}\text { SOUZA, L. C. } \\
\text { A. B. }\end{array}$ & $\begin{array}{l}\text { A problematização do princípio da precaução na } \\
\text { formação do técnico agrícola: reflexões para o } \\
\text { enfrentamento da racionalidade instrumental a partir de } \\
\text { uma questão sociocientífica }\end{array}$ \\
\hline $\begin{array}{l}\text { BDTD } \\
06\end{array}$ & 2016 & $\begin{array}{l}\text { ANDRADE, M. } \\
\text { A. S. }\end{array}$ & $\begin{array}{l}\text { Construção e aplicação de uma sequência didática } \\
\text { colaborativa a partir de uma questão sociocientífica sobre } \\
\text { agrotóxicos na perspectiva CTSA }\end{array}$ \\
\hline CTD - 07 & 2016 & $\begin{array}{l}\text { RIBEIRO, K. D. } \\
\text { F. }\end{array}$ & $\begin{array}{l}\text { Formação de professores de Ciências Naturais em uma } \\
\text { perspectiva interdisciplinar e crítica: Reflexões sobre a } \\
\text { contribuição da vivência com questões sociocientíficas na } \\
\text { mobilização e aprendizagem de conhecimentos para a } \\
\text { docência }\end{array}$ \\
\hline $\begin{array}{l}\text { BDTD - } \\
08\end{array}$ & 2018 & $\begin{array}{l}\text { ANDRADE, F. } \\
\text { F. }\end{array}$ & $\begin{array}{l}\text { Agrotóxico e agricultura: uma abordagem socioambiental } \\
\text { reflexiva no ensino de Química }\end{array}$ \\
\hline $\begin{array}{l}\text { BDTD - } \\
09\end{array}$ & 2018 & SANTOS, T. S. & $\begin{array}{l}\text { Alfabetização científica e o uso de questões } \\
\text { sociocientíficas no ensino de ecologia: uma experiência } \\
\text { no contexto de Lagarto - SE }\end{array}$ \\
\hline CTD - 10 & 2019 & $\begin{array}{l}\text { BARBOSA, F. } \\
\text { M. }\end{array}$ & $\begin{array}{l}\text { Ensino de química e o uso de agrotóxicos: saberes } \\
\text { conjuntos entre escola e comunidade }\end{array}$ \\
\hline $\begin{array}{l}\text { BDTD } \\
11\end{array}$ & 2019 & $\begin{array}{l}\text { FONSECA, E. } \\
\text { M. }\end{array}$ & $\begin{array}{l}\text { Abordagem de temas no Ensino de Ciências: Reflexões } \\
\text { para processos formativos de professores }\end{array}$ \\
\hline
\end{tabular}

*Compreende-se por BDTD (Biblioteca Digital Brasileira de Teses e Dissertações) e CTD (Catálogo de Tese e Dissertações da Capes).

Partindo de nove dissertações e duas teses analisadas podemos verificar algumas articulações/aproximações com os principais descritores encontrados e reunidos nas nuvens de palavras que se relacionam a CTS e a Paulo Freire e como estes se articulam a temática agrotóxicos nos trabalhos.

Na figura 1, os termos que se destacaram nas pesquisas selecionadas foram: CTS, Ciência, Tecnologia, Sociedade e Ambiente (CTSA), Contextualização, Tomada de decisão, Questões Sociocientíficas (QSC), PLACTS, Temas sociais, Interdisciplinaridade, Movimento CTS (Nuvem A) e Problematização, Três Momentos 
Pedagógicos, Tema gerador, Conscientização, Educação bancária, práxis, diálogo, autonomia, educação libertadora (Nuvem B). É preciso salientar que foram selecionados os termos que caracterizavam/aproximavam ou se articulavam a perspectiva CTS e freireana. Não foi enumerado a quantidade de vezes que os termos apareceram nas dissertações ou teses, somente se elas apareceram.

Figura 1 - Nuvem A: Perspectiva CTS e Nuvem B: Perspectiva Freireana, articuladas aos agrotóxicos
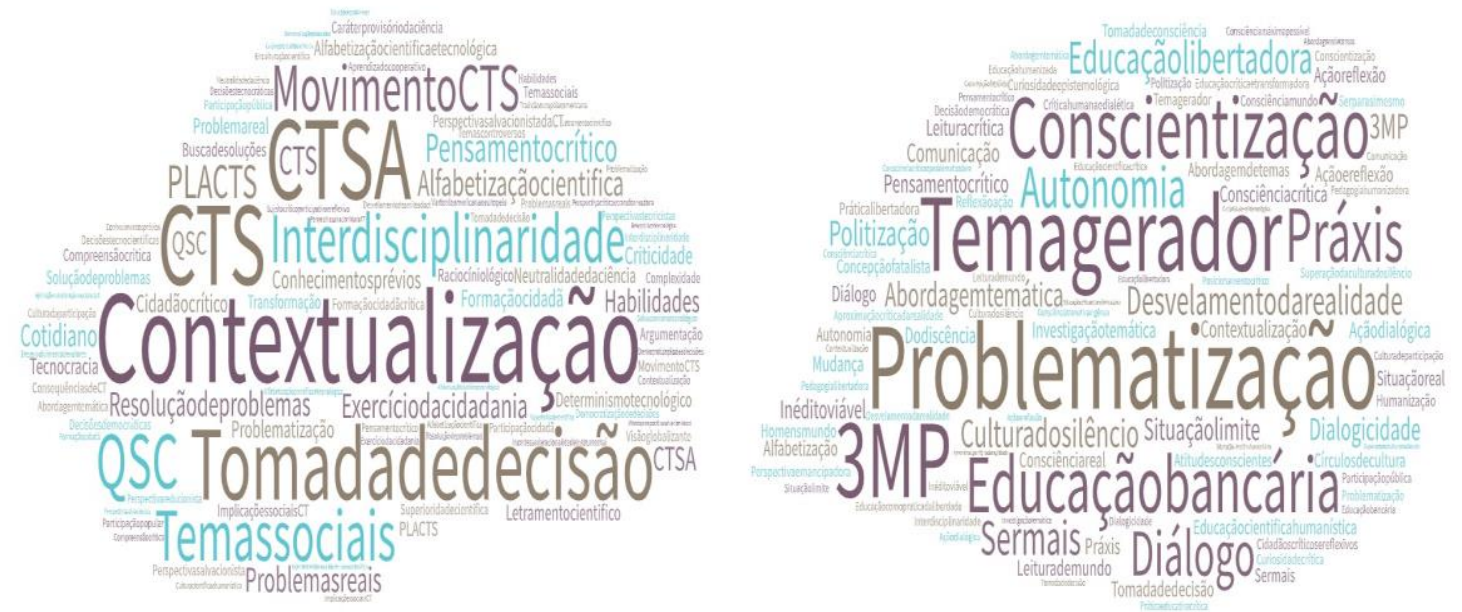

Fonte: os autores (2021)

Almeida (2009), se propôs a analisar a aprendizagem em Química a partir da abordagem CTS, utilizando o tema Agrotóxicos para caracterizar o ensino, juntamente com as vivências da população de um Assentamento e as implicações na formação do Técnico Agrícola. O conceito de problematização é abordado para desenvolver a temática dos agrotóxicos com os estudantes a partir dos Três Momentos Pedagógicos e o termo CTS é utilizado para desenvolver a habilidade crítica dos estudantes. As principais palavras referidas na dissertação quanto a CTS e Freire foram: Tema gerador, educação científica humanística, ação dialógica, educação bancária, problematização, conscientização, tomada de decisão, formação cidadã, solução de problemas, contextualização, caráter provisório da ciência.

O trabalho do pesquisador traz os conceitos de tema gerador definido como os agrotóxicos, e o diálogo, cuja intenção foi propiciar uma educação dialógica problematizadora (FREIRE, 2019). O tema gerador agrotóxicos, neste trabalho, não emerge a partir da investigação temática, como proposta por Paulo Freire (2019), é um tema escolhido anteriormente pelos pesquisadores. Quanto a educação dialógica, esta possibilita a libertação do oprimido, ao contrário da educação bancária que mantém o processo de opressão (FREIRE, 2019).

Por sua vez, Gotardi (2012) em sua pesquisa, tratou da construção e a avaliação de uma sequência didática sobre o uso dos agrotóxicos, norteada pelo movimento CTS e 
pela concepção educacional de Paulo Freire para o ensino de química. Na pesquisa houve a adaptação de alguns aspectos da Investigação temática em Freire e a sequência didática sobre a temática dos agrotóxicos foi elaborada e desenvolvida a partir dos Três Momentos Pedagógicos. As principais palavras que apareceram na dissertação relacionadas a Paulo Freire e CTS foram: contextualização, interdisciplinaridade, problematização, diálogo, desvelamento da realidade, compreensão crítica, práxis, democratização das decisões, superação da cultura do silêncio, educação bancária, situação-limite, autonomia, Movimento CTS, CTSA, perspectiva salvacionista, determinismo tecnológico, entre outros termos.

Nos resultados, Gotardi (2012), verificou as contribuições da educação dialógica e problematizadora que permeou toda a pesquisa, concluindo que os educandos puderam perceber, criticamente, suas posturas diante das situações problema. Constatou-se, as contribuições da perspectiva CTS, na medida em que os estudantes passaram a superar o mito da concepção salvacionista da ciência e da tecnologia, discutido por Auler (2002). Eles tiveram que refletir sobre a necessidade ou não do uso dos agrotóxicos nas lavouras, pensando não só no desenvolvimento científico-tecnológico, mas também nas implicações sociais do mesmo.

O estudo de Buffolo (2014), investigou a contribuição de uma sequência didática com o tema agrotóxicos na articulação de conhecimentos químicos e questões socioambientais com alunos do ensino médio. A referida sequência, foi elaborada de acordo com os pressupostos da orientação CTS e dos três momentos pedagógicos de Delizoicov. Os principais termos CTS e freireanos destacados na dissertação foram: educação libertadora, Três Momentos Pedagógicos, abordagem temática, situaçõesproblema, temas geradores, educação problematizadora, CTS, CTSA, contextualização, cidadão crítico, tomada de decisão, busca de soluções, participação cidadã e democrática, movimento CTS, neutralidade da ciência.

Conforme Buffolo (2014), a abordagem de temas socioambientais vem ao encontro dos pressupostos CTS, deve propiciar a reflexão do aluno sobre questões reais do seu contexto social e ambiental, tornando-se comprometido e, se possível, transformador de sua realidade. Os resultados obtidos na pesquisa revelaram que, mesmo tendo a grande maioria dos estudantes uma boa compreensão sobre o tema, apresentando poucas dificuldades ao relacioná-lo com o conhecimento químico, as atividades desenvolvidas durante a intervenção pedagógica mostraram mudanças positivas nas 
percepções dos alunos a respeito das implicações sociais e ambientais provocadas pelo uso inadequado dos agrotóxicos.

Carmo (2014) realizou em sua dissertação um estudo teórico-reflexivo com o intuito de contribuir para a análise das interfaces da EA e CTS e sua utilização no ensino de Química, bem como sua contribuição para a formação de cidadãos na perspectiva crítica e transformadora. As palavras-chave relacionadas a Paulo Freire e CTS encontradas foram: Tema gerador, educação crítica e transformadora, conscientização, aproximação crítica da realidade, problematização, CTS, formação cidadã crítica, transformação, contextualização, CTSA, temas sociais, interdisciplinaridade, decisões democráticas, resolução de problemas, conhecimentos prévios, tomada de decisão, alfabetização cientifica movimento CTS e neutralidade da ciência.

O descritor agrotóxico aparece na dissertação de Carmo (2014), quando ele analisa dissertações que traz o termo. E a perspectiva freireana emerge para discutir, entre outras coisas, a conscientização, como uma das principais ações na educação crítica e transformadora na EA. A autora se apoia em Freire, dizendo que os temas socioambientais podem ser trabalhados por meio da conscientização, contribuindo para a racionalização das atitudes da situação a ser enfrentada com caráter crítico em coletividade. Os resultados indicam, a partir da análise das teses e dissertações, que, na maioria dos trabalhos, CTS e EA são tratados como vertentes muito próximas.

A tese de Souza (2016), buscou investigar as potencialidades pedagógicas da inserção do Princípio da Precaução em discussões sociocientíficas para o enfrentamento da Racionalidade Instrumental na formação do técnico agrícola, explorando-se uma situação do contexto agrícola mato-grossense. As principais palavras encontradas na tese quanto aos aspectos freireanos e de CTS foram: autonomia, consciência crítica, concepção fatalista, problematização, diálogo, situação limite, inédito viável, tomada de consciência, educação como prática da liberdade, desvelamento da realidade, educação cientifica humanística, tema gerador, conscientização, os Três Momentos Pedagógicos, círculos de cultura, consciência real, consciência máxima possível, ser mais, CTS, incertezas da racionalidade instrumental, alfabetização cientifica e tecnológica, neutralidade da ciência, temas controversos, questões sociocientíficas, cultura científica e humanística, tomada de decisão, contextualização, tecnocracia e perspectiva reducionista.

A pedagogia freireana de educação permeou toda a análise de dados realizada na tese por se tratar da ideologia educacional defendida na tese. Além disso, esta pesquisa 
visou promover reflexões com os professores formadores de técnicos agrícolas sobre os modelos de racionalidade presentes nessa modalidade de ensino e suas compreensões sobre CTS a fim de estimular a inserção de uma racionalidade socioambiental, que integre preocupações com o bem-estar humano à qualidade ambiental, no ensino para a formação do técnico agrícola. Como resultado da tese, as atividades demonstraram o potencial da inserção do Princípio da Precaução em discussões sociocientíficas sobre temas ambientais, com vista ao enfrentamento da racionalidade instrumental na formação do técnico agrícola. Como indícios do êxito desse processo, cita-se: a desestabilização do conhecimento dos professores para responder à questão problematizadora da discussão; a tomada de consciência deles sobre o uso de agrotóxicos como um problema socioambiental e suas manifestações favoráveis à necessidade de se promover a formação do técnico agrícola que supere o tecnicismo e pragmatismo vigente - característicos da racionalidade instrumental.

Andrade (2016) em sua dissertação, avaliou a construção e a aplicação colaborativa de uma sequência didática, a partir de uma Questão Sociocientífica sobre agrotóxicos, tendo como contexto a perspectiva CTSA. As palavras-chave que prevaleceram no estudo quanto a proposta de Freire e de CTS foram: Politização, perspectiva emancipadora, crítica humana e dialética, abordagem temática, cidadãos críticos e reflexivos, consciência crítica, leitura crítica, cultura do silêncio, dialogicidade, problematização, educação bancária, comunicação, ação-reflexão, práxis, desvelamento da realidade, curiosidade epistemológica, CTSA, QSCs, interdisciplinaridade, pensamento crítico, contextualização, tomada de decisão, resolução de problemas, alfabetização científica e tecnológica, cultura da participação, perspectivas tecnicistas, salvacionismo tecnológico e movimento CTS.

A aplicação da sequência didática gerou a mobilização de conteúdos conceituais, procedimentais e atitudinais pelos estudantes, conforme a organização dos objetivos de aprendizagem no planejamento didático. A abordagem da QSC no contexto da educação CTSA contribuiu, por meio da mobilização destes conteúdos na formação política, científica e cidadã dos envolvidos na pesquisa, culminando na realização de ações sociopolíticas. O tema agrotóxico, sendo potencialmente significativo para o ensino de Ciências, pode permitir aos estudantes a compreensão das interfaces existentes entre CTSA, ampliando as suas visões de mundo e o seu conhecimento científico. À medida que permite explicitar as relações CTSA, trabalhar o tema agrotóxicos permite ao professor, do ponto de vista metodológico, inovar o seu ensino em uma perspectiva 
sociocultural, partir do cotidiano dos estudantes para permitir que eles se apropriem de forma crítica e significativa o conhecimento.

Ribeiro (2016), em sua tese, investigou os processos de mobilização e aprendizagem de conhecimentos para a docência visando à formação em uma perspectiva interdisciplinar e crítica, por futuros professores de Ciências Naturais durante uma ação formativa com abordagem de questão sociocientífica. As palavras-chave que predominaram no estudo quanto a proposta de Freire e de CTS foram: educação bancária, educação libertadora, consciência crítica e problematizadora, dialogicidade, autonomia, prática educativa crítica, curiosidade epistemológica, curiosidade crítica, tomada de decisão, conscientização, leitura de mundo, cultura do silêncio, ser mais, reflexão ação, tema gerador, humanização, CTSA, QSC, desvelamento dos mitos da CT, temas sociais, interdisciplinaridade, complexidade, contextualização, exercício da cidadania, alfabetização cientifica e tecnológica, movimento CTS, participação popular, tomada de decisão, democratização das decisões, pensamento crítico, resolução de problemas e desenvolvimento de valores.

Utilizou Paulo Freire para discussão teórica no desvelamento do problema socioambiental. A autora, baseada em Auler, Dalmolin e Fenalti, diz que as articulações entre CTS e Paulo Freire resultam da compreensão de que a busca de participação, de democratização das decisões em temas sociais envolvendo Ciência, Tecnologia, objetivo do movimento CTS, contém elementos comuns à matriz teórica-filosófica adotada por Freire, considerando que seu fazer educacional parte do pressuposto da vocação ontológica do ser humano em "ser mais" (ser sujeito histórico e não objeto), havendo, para tal, a necessidade da superação da "cultura do silêncio" e propicia a "leitura crítica do mundo". Os resultados da pesquisa indicaram que a aprendizagem de conhecimentos para a docência ocorre no envolvimento de análise de questões sociocientíficas fornecendo elementos que auxiliam na reflexão sobre possibilidades de contemplar uma formação de professores de Ciências em uma perspectiva interdisciplinar e crítica.

Em sua dissertação, Andrade (2018), analisou as contribuições de uma sequência didática por meio dos Três Momentos Pedagógicos com o enfoque CTS no ensino de Química a partir da temática agrotóxico como promotora de aprendizagem em Química e para a formação do aluno como cidadão. As palavras-chave encontradas na pesquisa relacionadas a Paulo Freire e CTS foram: Três Momentos Pedagógicos, educação libertadora, dialogicidade, problematização, CTS, temas sociais, movimento CTS, exercício da cidadania, tomada de decisão, pensamento crítico, resolução de problemas, 
contextualização e aplicações e implicações sociais da CT. Abordou-se a relevância do ensino de Química pelo viés da perspectiva CTS, relacionando as múltiplas dimensões desse processo com a propostas pautadas nessas interações. Paulo Freire é utilizado no trabalho como sustentação sutil teórica em relação a prática social produzindo mudanças qualitativas em busca de novos valores que venham dar uma nova direção a prática social e que para isso é preciso o conhecimento crítico aprofundado da realidade, da problematização e da dialogicidade.

Os resultados da pesquisa mostraram que a sequência didática contribuiu para a apropriação dos conceitos químicos e que as discussões relacionadas à temática e as interações CTS proporcionaram mudanças de percepção dos alunos quanto aos efeitos do desenvolvimento científico tecnológico na sociedade. Também permitiu identificar diferentes possibilidades de dinamização do ensino aprendizagem com maior participação e interesse dos alunos, de forma a ser útil para o ensino de Química.

A pesquisa de Santos (2018) analisou as potencialidades e limitações da utilização de QSC no ensino de Ecologia, de modo a contribuir para a Alfabetização Científica de estudantes do $6^{\circ}$ ano do Ensino Fundamental da rede municipal de Lagarto, região centrosul de Sergipe. As palavras-chave encontradas no texto referentes a Paulo Freire e CTS foram: Alfabetização, conscientização, pensamento crítico, educação libertadora, problematização, educação bancária, CTSA, QSC, alfabetização cientifica, questão sociocientifica, participação cidadã, alfabetização cientifica e tecnológica, letramento cientifico, enculturação cientifica, movimento CTS, contextualização, determinismo tecnológico, perspectiva salvacionista da CT, decisões tecnocráticas, tomada de decisão, problemas reais.

O enfoque CTSA é trazido na pesquisa como embasamento teórico e como concepção dos professores, cujas respostas se encaixaram nas categorias: as interações CTSA, o enfoque CTSA na educação cientifica e ambiental dos cidadãos, a capacidade de sensibilizar os estudantes acerca dos problemas ambientais, o enfoque CTSA como um conjunto de metodologias. A perspectiva freireana é trazida na pesquisa de forma sutil como parte das discussões teóricas quando problematiza os conceitos de educação bancária para uma educação libertadora e de Alfabetização-conscientização. Conclui-se, portanto, que os estudantes trazem consigo uma gama de conhecimentos, adquiridos principalmente na sua vivência diária, que precisam ser trabalhados na sala de aula, para que assim a aprendizagem de novos conteúdos possa ter sentido e efetivamente contribua para a formação cidadã dos discentes. Para que isso aconteça é necessário que o docente 
se preocupe em utilizar os assuntos científicos como meios para entender uma problemática social, abordando questões reais e atuais.

Barbosa (2019), objetivou relacionar os saberes populares de agricultores familiares, pais de alunos do $9^{\circ}$ ano, a partir do tema gerador agrotóxicos, de modo a conscientizá-los sobre os riscos do uso desenfreado desses produtos, bem como estudálos por meio do assunto substância e mistura. Foi aplicada aos alunos uma proposta de ensino, elaborada a partir dos pressupostos teóricos estabelecidos pelos Parâmetros Curriculares Nacionais e presentes no movimento CTSA. A autora enfatiza temas geradores e o Ensino de Química, fazendo um paralelo entre o tema agrotóxico e o enfoque CTSA no processo de construção de conhecimentos. Desenvolve a temática dos agrotóxicos como tema gerador, no entanto, para Paulo Freire o tema gerador se alcança a partir da Investigação temática da realidade, o que não ocorre nesse trabalho. As palavras-chave encontradas na pesquisa em relação a Paulo Freire e CTS foram: Problematização, atitudes conscientes, prática libertadora, educação cientifica crítica, conscientização, politização, tema gerador, comunicação, educação humanizada, interdisciplinaridade, educação bancária, diálogo, CTSA, temas sociais, contextualização, tomada de decisão, movimento CTS.

Os dados obtidos a partir da pesquisa da autora mostraram avanço e um bom desempenho dos estudantes, quanto à resolução de problemas com o assunto substância e mistura. Após a aplicação da proposta, observou-se também que os alunos perceberam as implicações sociais e ambientais provocadas pelo uso inadequado dos agrotóxicos e apresentaram maior compreensão sobre o tema, evidenciando a importância de introduzir questões socioambientais no Ensino de Química em uma perspectiva CTSA.

Fonseca (2019), trabalha em sua pesquisa com temas no Ensino de Ciências, inspirado no referencial freireano e em repercussões da Educação CTS/PLACTS. O objetivo foi identificar e compreender as potencialidades e limitações na abordagem de temas, a partir da compreensão de professores de Ciências da rede de ensino municipal de Dom Pedrito sobre a temática do agrotóxico. Na dissertação do autor, a abordagem de Paulo Freire e CTS estiveram bem articuladas e durante a leitura emergiram as seguintes palavras-chave: abordagem temática, problematização, contextualização, pedagogia humanizadora, pedagogia libertadora, consciência mundo, homens mundo, tomada de decisão, participação pública, decisão democrática, diálogo, situação real, conscientização, ser mais, posicionamento crítico, tema gerador, investigação temática, situação limite, Três Momentos Pedagógicos, cultura do silêncio, leitura de mundo, 
dodiscência, consciência transitiva ingênua, práxis, ser para si mesmo, cultura de participação, CTS, PLACTS, contextualização, problematização, tomada de decisão, criticidade, problemas reais, argumentação, mito da perspectiva salvacionista CT.

Os resultados dessa pesquisa apontaram que as professoras não possuem clareza sobre a concepção de temas e conteúdos, bem como compreendem que há uma necessidade de cumprir o programa curricular sistematicamente. Diante disso, questões do contexto são abordadas para trabalhar conteúdos conceituais. Esses aspectos sinalizam indicativos de passividade, que acabam contribuindo para a perpetuação de uma cultura do silêncio. Porém, também foi possível identificar uma abertura para trabalhar questões do contexto e do interesse dos estudantes em sala de aula e, ainda, o reconhecimento sobre a importância da abordagem do tema agrotóxico. A sistematização dos resultados permitiu elaborar um Ensaio teórico-prático sobre o referido tema, como possibilidade de abordagem tanto na Educação Básica quanto na formação inicial e continuada de professores. Por fim, defende-se a importância da abordagem de temas, baseada em articulações CTS/PLACTS-Freire como potencialidade de mobilizar uma prática pedagógica problematizadora e contextualizada.

\section{CONSIDERAÇÕES FINAIS}

Nas análises dos dados procuramos identificar o número de trabalhos que convergiam conjuntamente para a temática dos Agrotóxicos, CTS, e Paulo Freire no Ensino de Ciências, nas nove dissertações e nas duas teses encontradas na BDTD e na CTD. Além da perspectiva teórica CTS, também buscamos dar significado aos dados encontrados nos apoiando nas ideias do pensador Paulo Freire o qual contribuiu na construção de novas reflexões acerca do ensino de Ciências no que se refere à perspectiva emancipadora, crítica e, principalmente, humana e dialética.

A perspectiva humanística de Paulo Freire se constitui como um referencial para pensarmos a educação CTS, compartilhando com ela objetivos que conferem ao ensino de Ciências um caráter político, reflexivo e crítico, tendo em vista que existe a necessidade de mentes que sejam capazes de analisar de forma qualitativa os benefícios trazidos pela ciência e tecnologia na sociedade.

A temática dos agrotóxicos, sendo potencialmente significativo para o ensino de Ciências, pode permitir a compreensão das interfaces existentes entre CTS, ampliando as visões de mundo e o conhecimento científico. À medida que permite explicitar as relações 
CTS, trabalhar o tema agrotóxicos permite inovar o ensino em uma perspectiva sociocultural, de forma crítica e significativa ao conhecimento.

Dessa forma as pesquisas analisadas retratam uma articulação envolvendo o enfoque CTS/CTSA/PLACTS, conceitos relacionados a perspectiva freireana e os agrotóxicos. Em algumas publicações estiveram mais articuladas com as temáticas e em outras vezes menos.

Foi possível perceber nas dissertações e teses, que no total dos onze trabalhos, sete delas trataram CTS na perspectiva de CTSA, dando maior visibilidade ao aspecto do Ambiente, isso remete a problemática ambiental discutida que são os agrotóxicos. Das onze publicações, quatro delas deram maior ênfase a perspectiva CTS, sendo uma delas para o PLACTS. Esta última trouxe a importância de discutir as políticas públicas e os problemas sociais a partir da localidade. Junto destas siglas, os trabalhos apresentaram palavras articuladas como a contextualização, tomada de decisão, temas sociais, QSC, interdisciplinaridade, pensamento crítico, resolução de problemas, entre outros, conforme pudemos ver na nuvem de palavras A acima.

A perspectiva freireana trouxe diversos conceitos envolvidos com a teoria de Paulo Freire, como: tema gerador, problematização, Três Momentos Pedagógicos, conscientização, educação bancária, diálogo, autonomia, educação libertadora, ser mais, práxis, cultura do silêncio, desvelamento da realidade, entre outros, conforme a nuvem de palavras B acima. Para Paulo Freire, a educação dialógica liberta os oprimidos, enquanto a educação bancária é a educação dos opressores. O diálogo e a problematização são categorias centrais nas discussões do autor.

\section{REFERÊNCIAS}

ALMEIDA, M. T. O agrotóxico como tema problematizador no ensino de Química na formação técnico agrícola. 2009. Dissertação (Mestrado em Educação Agrícola) - Universidade Federal Rural do Rio de Janeiro, Seropédica, 2009.

ANDRADE, M. A. S. Construção e aplicação de uma sequência didática colaborativa a partir de uma questão sociocientífica sobre agrotóxicos na perspectiva CTSA. 2016. Dissertação (Mestrado em Ensino, Filosofia e História das Ciências) - Universidade Federal da Bahia e da Universidade Estadual de Feira de Santana, Salvador, 2016. 
ANDRADE, F. F. Agrotóxico e agricultura: uma abordagem socioambiental reflexiva no ensino de Química. 2018. Dissertação (Mestrado em Formação de Professores) - Universidade Estadual da Paraíba, Campina Grande, 2018.

AULER, D. Interações entre Ciência-Tecnologia-Sociedade no Contexto da Formação de Professores de Ciências. 2002. Tese (Doutorado em Educação: Ensino de Ciências Naturais) - Universidade Federal de Santa Catarina, Florianópolis, 2002.

AULER, D. Por que a educação em ciência, tecnologia e sociedade vem andando devagar? In: SANTOS, W.; AULER, D. (Orgs). CTS e Educação científica: desafios, tendências e resultados de pesquisa. Brasília: UNB, 2011.

AULER, D.; DELIZOICOV, D. Investigação de temas CTS no contexto do pensamento latino-americano Linhas Críticas, vol. 21, núm. 45, maio-agosto, 2015. Universidade de Brasília. Brasília.

AULER, D. Cuidado! Um cavalo viciado tende a voltar para o mesmo lugar. Curitiba: Appris, 2018.

BARBOSA, F. M. Ensino de química e o uso de agrotóxicos: saberes conjuntos entre escola e comunidade. 2019. Dissertação (Mestrado em Ensino de Ciências e Educação Matemática) - Universidade Estadual da Paraíba, Campina Grande, 2019.

BUFFOLO, A. C. C. Agrotóxicos: uma proposta socioambiental reflexiva para desenvolver conhecimentos químicos numa perspectiva CTS. 2014. Dissertação (Mestrado em Educação para Ciência e Matemática) - Universidade Estadual de Maringá, Maringa, 2014.

CARMO, T. Aproximações entre a educação ambiental e o movimento Ciência, Tecnologia e Sociedade: um olhar sobre dissertações e teses no ensino de química. 2014. Dissertação (Mestrado em Educação para Ciência e Matemática) - Universidade Estadual de Maringá, Maringá, 2014.

CARSON, R. Primavera Silenciosa. São Paulo: Gaia, 2010.

FONSECA, E. M. Abordagem de temas no Ensino de Ciências: Reflexões para processos formativos de professores. 2019. Dissertação (Mestrado Acadêmico em Ensino) - Universidade Federal do Pampa, Bagé, 2019. 
FREIRE, P. Pedagogia da esperança: um reencontro com a pedagogia do oprimido. Rio de Janeiro/São Paulo: Paz e Terra, 2016.

FREIRE, P. Pedagogia do Oprimido. Rio de Janeiro/São Paulo: Paz e Terra, 2019.

GOTARDI, O. L. N. Agrotóxicos e meio ambiente - abordagem CTS numa perspectiva freireana para o ensino de química em culturama-MS. 2012. Dissertação (Mestrado em Ensino de Ciências) - Universidade Federal de Mato Grosso do Sul, Campo Grande, 2021.

RIBEIRO, K. D. F. Formação de professores de Ciências Naturais em uma perspectiva interdisciplinar e crítica: Reflexões sobre a contribuição da vivência com questões sociocientíficas na mobilização e aprendizagem de conhecimentos para a docência. 2016. Tese (Doutorado em Educação em Ciências e Matemática) Universidade Federal de Mato Grosso, Cuiabá, 2016.

ROMANOWSKI, J.; ENS, R. As pesquisas denominadas do tipo "Estado da Arte". Diálogo Educ., Curitiba, v. 6, n.19, p.37-50, set./dez. 2006.

SANTOS, T. T. Alfabetização científica e o uso de questões sociocientíficas no ensino de ecologia: uma experiência no contexto de Lagarto - SE. 2018. Dissertação (Mestrado em Ensino de Ciências e Matemática) - Universidade Federal de Sergipe, São Cristóvão, 2018.

SOUZA, L. C. A. B. A problematização do princípio da precaução na formação do técnico agrícola: reflexões para o enfrentamento da racionalidade instrumental a partir de uma questão sociocientífica. 2016. Tese (Doutorado em Educação Científica e Tecnológica) - Universidade Federal de Santa Catarina, Florianópolis, 2016.

VARSAVSKY, O. Por uma política científica nacional. Rio de Janeiro: Paz e Terra, 1976.

Recebido em: 31 de maio de 2021.

Aceito em: 08 de junho de 2021. 